\title{
Renal transplantation in children less than 5 years of age
}

\author{
GIANFRANCO RIZZONI, MOHAMMAD H MALEKZADEH, ALFRED J PENNISI, \\ ROBERT B ETTENGER, CHRISTEL H UITTENBOGAART, AND RICHARD N FINE
}

Department of Paediatrics, University of Padua, Italy, the Department of Pediatrics, University of Southern California School of Medicine, and the Dialysis and Transplant Program, Children's Hospital of Los Angeles, USA

SUMMARY 19 young children (less than 5 years old) have received 31 renal transplants from 4 live relatives and 27 cadaver donors. The 2-year allograft survival rate for the patients receiving their 1st allograft from the 4 live donors was $75 \pm 22 \%$ while that for the patients receiving their 1st allograft from 15 cadaver donors was $26 \pm 11 \%$. 10 children are currently surviving with functioning allographs ( 7 cadavers and 3 live relatives); 4 have died and 5 are undergoing dialysis after the loss of at least one allograft. Despite the poor allograft survival rate the fact that 7 children are surviving with cadaver allografts indicates that the lack of a living related donor should not prevent transplants in young children.

Haemodialysis and renal transplantation are acceptable treatments for older children and adolescents with end stage renal disease. However, many paediatric nephrologists hesitate to recommend such treatment for young children and infants.

Reports of renal transplants in children under age 5 years are rare and results are sometimes discouraging. $^{1-8}$ In 1978 Hodson and co-workers? reported a large series of renal transplants from 19 related live donors (LD) and 4 cadaver donors (CD) in children less than 5 years old. Their results were similar to those for older children. We now give our experience with 31 renal transplants performed in 19 children under age 5 years. Most of the allografts were from cadaver donors.

\section{Materials and methods}

Between September 1968 and March 1979, 19 children (aged between 11 months and 5 years 1 month) received 31 renal allografts from $4 L D$ and 27 CD. 10 recipients received one allograft, 7 received two, 1 received three, and 1 received four allografts. Eight recipients were girls and 11 were boys. The average age at the time of the initial transplant was 3 years 1 month; 2 infants were 11 months.

The primary renal diseases of the 19 children were: focal glomerulosclerosis (3), membranoproliferative glomerulonephritis (2), obstructive uropathy (4), hypoplastic or dysplastic kidneys, or both,
(3), haemolytic uraemic syndrome (2), cortical necrosis (1), medullary cystic disease (1), polycystic kidney disease with congenital hepatic fibrosis (1), infantile nephrotic syndrome (1), and bilateral Wilms's tumour (1).

Haemodialysis was started before transplantation in 17 patients and 2 children were treated with peritoneal dialysis. ${ }^{9}$ The average time of dialysis before initial transplantation was 5 months (range 5 days to 13 months). Bilateral nephrectomy was performed before transplantation in 6 recipients, and simultaneously with transplantation in 3 recipients. The remaining 10 recipients did not undergo bilateral nephrectomy.

During the period of dialysis each patient received at least one blood transfusion (mean 9.7; range 1-30 units). Despite the blood transfusion (stored sedimented red blood cells) only 2 patients had preformed lymphocytotoxic antibodies before receiving their initial allografts.

The ages of the donors of the $27 \mathrm{CD}$ allografts were $>12$ years in ten cases, between 4 and 6 years in four, and $<2$ years in nine cases. All 4 LD allografts were from mothers who were between 27 and 30 years of age.

An extraperitoneal approach, with placement of the allograft in the iliac fossa as previously described, ${ }^{10}$ was used in each instance. The allograft ureter was reimplanted into the bladder via a ureteroneocystostomy.

Immunosuppressive therapy consisted of azathio- 
prine and prednisone as previously described. ${ }^{10}$ The amount of each drug was calculated according to weight of the patient. No recipient underwent thymectomy or splenectomy, and none received $x$-irradiation. Since September 1976, 7 recipients have had antithymocyte globulin in a dose by rosette protocol (Upjohn Co., Kalamazoo, Mich.). ${ }^{11}$ The criteria for the diagnosis of rejection and treatment schedule have been described. ${ }^{10}$

\section{Results}

Patient survival. Of the 19 recipients, 10 are currently surviving with functioning allografts $(71 \mathrm{st}$, 3 2nd), 4 have died, and 5 are undergoing dialysis while awaiting new allografts. The most recent serum creatinine level of the 10 recipients with functioning allografts is 0.3 to $6.0 \mathrm{mg} / 100 \mathrm{ml}(26.5$ to 530 $\mu \mathrm{mol} / \mathrm{l})$ with 8 receipients having a serum creatinine level $<1.0 \mathrm{mg} / 100 \mathrm{ml}(<88.4 \mu \mathrm{mol} / \mathrm{l})$. The low serum creatinine levels in these young children did not influence the prompt diagnosis of rejection episodes. The 1- and 2-year actuarial patient survival $( \pm$ SEM) was $83 \pm 9 \%$ and $75 \pm 11 \%$ respectively.

Two children died within the first month after their transplants, during the period when the $C D$ allograft was recovering from acute tubular necrosis. One recipient with a primary seizure disorder died with status epilepticus, and one recipient with biliary dysgenesis died with a bleeding diathesis. The other two deaths occurred in recipients with functioning allografts-one 4 months later from gastrointestinal haemorrhage, and one 18 months later from aspiration after a seizure.

Allograft survival. Three of the $4 \mathrm{LD}$ allografts are currently functioning 30 to 66 months after transplants. The 1- and 2-year actuarial survival rate for the 4 LD allografts was $100 \%$ and $75 \pm 22 \%$ respectively.

Of the $27 \mathrm{CD}$ allografts (15 1st, 9 2nd, 2 3rd, and 14 th), only 7 (4 1st, 32 nd) are currently functioning 1 to 91 months after the transplants. The 1- and 2year actuarial survival rate for all $27 \mathrm{CD}$ allografts was $41 \pm 10 \%$ and $31 \pm 10 \%$ respectively; for the $15 \mathrm{CD} 1$ st allografts it was $33 \pm 12 \%$ and $26 \pm 11 \%$ respectively.

Of the 21 (20 CD and 1 LD) allograft failures 7 were lost to irreversible acute rejection at 1 to 29 days after the transplants and 7 were lost to chronic rejection at 5 to 89 months after the transplants. Four recipients died with a functioning allograft as described, and 3 allografts were lost as a result of technical problems. The last group comprised haemorrhagic infarction of an anencephalic kidney secondary to high venous pressure from an arteriovenous fistula in the thigh, bleeding from the anastomotic site requiring allograft removal, and haemorrhagic infarction 24-48 hours after the transplant of an allograft from a 4-month-old donor with two renal arteries.

Complications. The significant complications encountered are shown in Table 1 . The recurrence of the primary disease was demonstrated in three allografts of 2 recipients. Nephrotic syndrome developed within the first week after the transplant in two successive allografts of a child whose original disease was the nephrotic syndrome and focal glomerulosclerosis, ${ }^{12}$ and histological evidence of the dense deposit variety of membranoproliferative glomerulonephritis was present in the allograft of another child. ${ }^{13}$

Growth. Linear growth and growth velocity were evaluated in 5 girls (Fig. 1) and 6 boys (Fig. 2) who survived with functioning grafts for at least one year. In 4 recipients ( $2 \mathrm{LD}$ and $2 \mathrm{CD})$ catch-up growth was observed after transplantation, however in no instance was the increase in growth velocity sufficient for the patient to reach the 5th centile. A growth rate of $>100 \%$ of normal continued for 2 years in 3 recipients, and for more than 3 years in 1 recipient. The appearance of renal failure (plasma creatinine level $>1.0 \mathrm{mg} / 100 \mathrm{ml}$ ) was associated with a greatly reduced growth rate in a recipient who had manifested previous catch-up growth. The introduction of alternate day corticosteroid therapy did not improve the growth rate in this recipient. In 2

\section{Table 1 Complications of transplants}

\begin{tabular}{ll}
\hline Complication & \\
\hline Haemorrhage $(\mathbf{n}=\mathbf{8})$ & 4 \\
Arterial anastomosis & 1 \\
Peritoneum & 1 \\
Bladder & $1^{*}$ \\
Intestinal & $1^{*}$ \\
Cerebral & \\
Infection (n $=14)$ & 1 \\
Varicella & 5 \\
Cytomegalovirus & 1 \\
Pneumocystis carinii & 5 \\
Pneumonia & 1 \\
Sepsis & 1 \\
Urethritis & \\
& 4 \\
Other (n $=18)$ & 3 \\
Hypertension & 4 \\
Recurrence of primary disease & 3 \\
'Ureteral complications' & 1 \\
Allograft infarction & 1 \\
Partial small bowel obstruction & $2^{*}$ \\
Seizures & \\
\hline Contributed to death. & \\
\hline
\end{tabular}

*Contributed to death. 


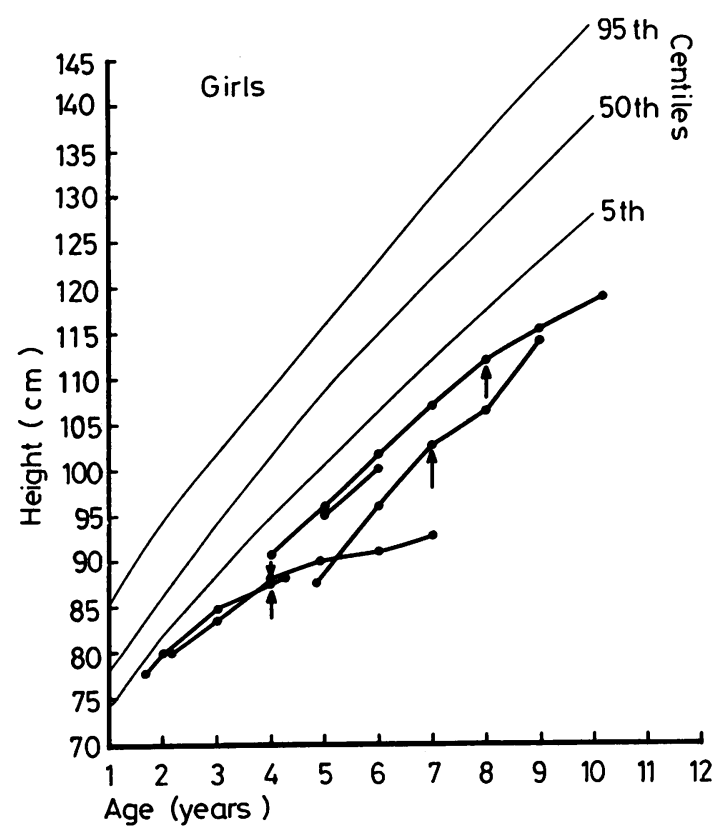

Fig. 1 Growth curve of girls with allografts functioning for more than one year.

$\uparrow$ Start of alternate day treatment. $\downarrow$ Start of chronic rejection.

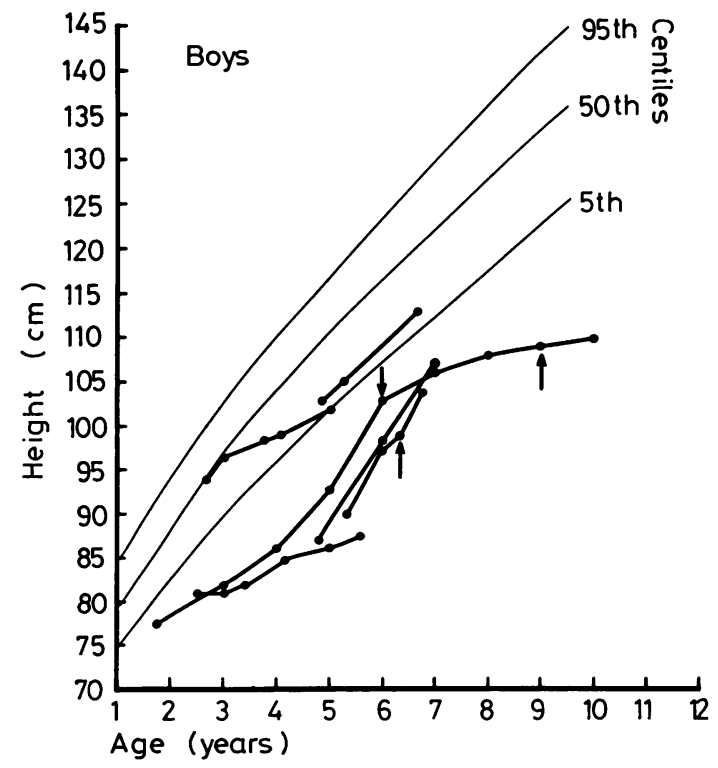

Fig. 2 Growth curve of boys with allografts functioning for more than one year.

$\uparrow$ Start of alternate day treatment. $\downarrow$ Start of chronic rejection. additional recipients who received alternate day therapy for $>1$ year, it was not possible to show an unequivocal improvement of the growth rate.

Rehabilitation. Of the 10 recipients with currently functioning allografts, 7 are attending regular elementary schools, 2 elementary schools for the handicapped, and 1 is at a nursery school. The 5 patients who are currently undergoing dialysis after allograft failure are attending regular elementary school (1), elementary school for the handicapped (1), receiving hospital teaching (1), and nursery schools (2). Of the 4 recipients who died, only 1 survived with a functioning allograft for $>1$ year and this patient had attended an elementary school.

\section{Discussion}

There have been few renal transplants in children under 5 years of age. As shown (Table 2), with the exception of the present series, 53 children have received $28 \mathrm{LD}$ and $33 \mathrm{CD}$ allografts. At the time of the reports $21(75 \%)$ LD and $12(36 \%)$ CD allografts were functioning. $15(28 \%)$ recipients died after transplants (10 CD and $5 \mathrm{LD}$ allograft recipients).

In the present series $10(53 \%)$ of the 19 children are currently surviving with functioning allografts (3 LD and $7 \mathrm{CD}), 4(21 \%)$ have died, and 5 are undergoing dialysis awaiting new allografts. The outcome with CD allografts however, is much poorer than our overall results with $\mathrm{CD}$ donor transplants in children. ${ }^{14}$

Various immunological and nonimmunological factors influence allograft outcome. The immunological factors include HLA antigen histocompatability, ${ }^{15}$ recipient immunological responsiveness as indicated by the development of lymphocytotoxic antibodies, ${ }^{16}$ and the good effect of blood transfusions before transplantation. ${ }^{17}$

Since HLA A and B antigen histocompatability has not affected our overall results, ${ }^{14}$ it is doubtful that it influenced allograft survival in these younger children. No recipient was highly presensitised ( $>50 \%$ lymphocytotoxic antibodies) before his initial allograft. Therefore, the poor outcome cannot be attributed to a prevalence of responder recipients. Similarly, each recipient received at least one blood transfusion before his initial transplant.

The nonimmunological factors adversely affecting allograft outcome are recipient age, ${ }^{18}$ coexistent multisystem disease, ${ }^{19}$ and primary renal disease. ${ }^{20}$ Recipients older than 45 years fare poorly after transplantation. The prevalence of concomitant cardiovascular disease in patients of this age is probably contributory. Coexistence of diabetes mellitus, oxalosis, or lupus erythematosis adversely 
Table 2 Summary of reported transplants performed in children aged under 5 years

\begin{tabular}{|c|c|c|c|c|c|c|c|}
\hline \multirow[t]{2}{*}{ Reference } & \multirow{2}{*}{$\begin{array}{l}\text { No of } \\
\text { patients }\end{array}$} & \multirow{2}{*}{$\begin{array}{l}\text { No of } \\
\text { transplants }\end{array}$} & \multicolumn{2}{|l|}{ Donors } & \multicolumn{3}{|l|}{ Outcome } \\
\hline & & & Cadaver & $\begin{array}{l}\text { Live } \\
\text { relative }\end{array}$ & $\begin{array}{l}\text { Graft } \\
\text { removed }\end{array}$ & $\begin{array}{l}\text { Graft } \\
\text { functioning }\end{array}$ & Patient died \\
\hline Martin et al 1 & 2 & 2 & 1 & 1 & & $\begin{array}{l}1 \\
1\end{array}$ & \\
\hline La Plante et al. ${ }^{2}$ & 2 & 2 & 2 & & 1 & & 1 \\
\hline Belzer et al. ${ }^{3}$ & 13 & 15 & 9 & 6 & $\begin{array}{l}1 \\
1\end{array}$ & $\begin{array}{l}3 \\
4\end{array}$ & $\begin{array}{l}5 \\
1\end{array}$ \\
\hline Cerilli et al. 4 & 1 & 1 & $\begin{array}{l}1 \\
7\end{array}$ & 2 & 4 & $\begin{array}{l}1 \\
1\end{array}$ & 2 \\
\hline $\begin{array}{l}\text { Lawson et al. }{ }^{5} \\
\text { Vidne et al. } 6\end{array}$ & $\begin{array}{l}7 \\
3\end{array}$ & $\begin{array}{l}9 \\
5\end{array}$ & 5 & & $\begin{array}{l}1 \\
5\end{array}$ & & 1 \\
\hline Hodson et al. ${ }^{7}$ & 21 & 23 & 4 & 19 & 4 & $\begin{array}{r}3 \\
12\end{array}$ & $\begin{array}{l}1 \\
3\end{array}$ \\
\hline $\begin{array}{l}\text { Kwun et al. } \\
\text { Present study }\end{array}$ & $\begin{array}{r}4 \\
19\end{array}$ & $\begin{array}{r}4 \\
31\end{array}$ & $\begin{array}{r}4 \\
27\end{array}$ & 4 & $\begin{array}{r}12 \\
1\end{array}$ & $\begin{array}{l}3 \\
7 \\
3\end{array}$ & $\begin{array}{l}1 \\
4\end{array}$ \\
\hline
\end{tabular}

affects allograft outcome because of the associated multisystem involvement. The primary renal disease may recur in the allograft thereby adversely affecting outcome.

Immunological factors accounted for two-thirds of the allograft failures in the present series. This incidence is similar to that in a large series. ${ }^{10}$ The nonimmunological causes of allograft loss were possibly related to recipient age. However, it is difficult definitively to implicate the recipients' age in the 3 technical failures or the 4 patient deaths. Two of the 3 technical failures could be related to donor age; however, anencephalic kidneys ${ }^{21}$ and kidneys from donors aged under 6 months have been used successfully. ${ }^{10}$ Since the recipients were managed in a paediatric institution experienced in the care of end stage renal disease, it is assumed that the nonimmunological failures were not attributable to unfamiliarity with general paediatric care.

The poor outcome of CD allografts indicates the need to justify this treatment for young children. Hodson et al., ${ }^{7}$ suggested that "when possible, this should be carried out using living related donor kidneys, thus avoiding long periods of dialysis, which in the small child is frequently associated with vascular access problems, malnutrition, and progressive renal osteodystrophy'. The problems encountered in dialysing small children are often difficult to manage; however, the criteria for donor selection should be based on predictability of improved outcome. Although current data on allografts show that LD is optimum regardless of recipient age, it must be remembered that nearly half of the CD recipients are currently surviving with functioning allografts. Therefore, the availability of a LD should not be a prerequisite for initiating treatment for end stage renal disease.

In addition to outcome, the two factors which should be considered before selecting a donor are growth and rehabilitation after transplantation. Hodson et al., in $1978,{ }^{7}$ reported that most LD allograft recipients who survived with functioning allografts for longer than 6 months demonstrated catch-up growth. However, few recipients maintained catch-up growth during the second and third years after their transplants.

The long-term results of linear growth in young children cannot be determined from the present series. However, catch-up or normal linear growth was observed in the $3 \mathrm{LD}$ allograft recipients whereas similar growth was observed in only 3 of the CD allograft recipients. In at least 2 instances, poor CD allograft function contributed to reduced growth velocity. ${ }^{22}$ Introduction of alternate day therapy has had a salutory effect on linear growth, but further data are needed in order to determine the effect of alternate day therapy on adult height.

\section{References}

1 Martin L W, Gonzales L L, West C D, Spitzer R, Reyes P M, Moore C C M. Clinical problems encountered in renal homotransplantation in children. $J$ Pediatr Surg 1970; 5 : 207-14.

2 LaPlante M P, Kaufman J J, Goldman R, Gonick H C, Martin D C, Goodwin W E. Kidney transplantation in children. Pediatrics 1970; 46: 665-77.

3 Belzer F O, Schweitzer R T, Holliday M, Potter D, Kountz S. Renal homotransplantation in children. $\mathbf{A m}$ J Surg 1972; 124: 270-8.

1 Cerilli G J, Nelsen C, Dorfmann L. Renal homotransplantation in infants and children with the hemolyticuremic syndrome. Surgery 1972; 71: 66-71.

5 Lawson R K, Talwalkar Y B, Musgrave J E, Campbell $R$ A, Hodges $C$ V. Renal transplantation in pediatric patients. J Urol 1975; 113: 225-9.

- Vidne B A, Leapman S B, Butt K, Gauthier B, Kountz $S$ L. Renal transplantation in children. Urology Int 1977; 32: 277-83.

7 Hodson E M, Najarian J S, Kjellstrand C M, Simmons R L, Mauer M. Renal transplantation in children ages 1 to 5 years. Pediatrics $1978 ; 61$ : 458-64. 
8 Kwun Y A, Butt K M H, Kim K H, Kountz S L, Moel $D$ I. Successful renal transplantation in a 3 month old infant. J Pediatr 1978; 92: 426-9.

9 Fine R N, De Palma J R, Lieberman E, Donnell G N, Gordon A, Maxwell M H. Extended hemodialysis in children with chronic renal failure. J Pediatr 1968; 73: 706-13.

10 Fine R N. Renal transplantation in children. Adv Nephrol $1975 ; 5: 97-120$.

11 Uittenbogaart C H, Robinson B J, Malekzadeh M H, Pennisi A J, Ettenger R B, Fine R N. The use of antithymocyte globulin (dose by rosette protocol) in pediatric renal allograft recipients. Transplantation 1979; 28: 291-3.

12 Malekzadeh M H, Heuser E T, Ettenger R B, et al. Focal glomerulosclerosis and renal transplantation. $J$ Pediatr. 1979; 95: 249-54.

13 Pennisi A J, Heuser E T, Malekzadeh M H, Uittenbogaart C H, Ettenger R B, Fine R N. Renal transplantation in children with membranoproliferative glomerulonephritis (abstract). In proceedings of the VIIth International Congress of Nephrology. Montreal, 1978.

14 Fine R N, Pennisi A J, Edelbrock H H, et al. Renal transplantation in children. Urology 1977; 9: Supplement, 61-71.

15 Dausset J, Hors J, Busson M, et al. Serologically defined HL-A antigens and long term survival of cadaver kidney transplants. N Engl J Med 1974; 290: 979-84.

16 Terasaki P I, Mickey M R, Kresler M. Presensitisation and kidney transplant failures. Postgrad Med J 1971; 47: 89-100.

17 Opelz G, Sengar D P S, Mickey M R, Terasaki P I. Effect of blood transfusions on subsequent kidney transplants. Transplant Proc 1973; 5 : 253-9.

18 Najarian J S, Simmons R L, Tallent M B, et al. Renal transplanation in infants and children. Ann Surg 1971; 174: 583-601.

19 Jervell J, Dahl B O, Jakobsen A, et al. Renal transplantation in insulin treated diabetics. Transplant Proc 1979; 11: 60-2.

20 Cameron J S, Turner D R. Recurrent glomerulonephritis in allografted kidneys. Clin Nephrol 1977; 7: 47-54.

21 Iitaka K, Martin L W, Cox J A, McEnery P T, West C D. Transplantation of cadaver kidneys from anencephalic donors. J Pediatr 93: 216-20.

22 Pennisi A J, Costin G, Phillips L S, et al. Linear growth in long term renal allograft recipients. Clin Nephrol 1977; 8: $415-21$.

Correspondence to Dr Richard N Fine, Children's Hospital of Los Angeles, 4650 Sunset Boulevard, Los Angeles, California 90027, USA.

Received 12 June 1979 